\title{
ADVERTISING BRANDS BY MEANS OF SOUNDS SYMBOLISM: THE INFLUENCE OF VOWELS ON PERCEIVED BRAND CHARACTERISTICS
}

\author{
Alina Duduciuc \\ National University of Political Studies and Public Administration \\ alina.duduciuc@comunicare.ro
}

\begin{abstract}
The aim of this study is to test the influence of sound symbolism on perceived characteristics of a brand as well as to highlight the importance of applied social psychology to current practice of advertising. Previous research showed that the phonetic structure of brand name communicates its characteristics, i.e. it drives consumers to assess certain features and performance of the product. I assumed that when consumers encounter an unknown brand name, they automatically infer characteristics from the meaning conveyed by the sounds (e.g. phonemes). Therefore, I supposed that a brand name for a shampoo (artificially created on experimental purpose) containing back vowel is evaluated better by consumers when they compare it to another brand name with front vowels. Furthermore, for the accuracy of responses, I used the semantic differential scale to measure the differences between two brands in terms of certain attributes of product. To this end, fifty students $(N=50)$ participated in a research based on questionnaire. As the results of the current research showed, the brand name with back vowel outnumbered the brand name with front vowel on two dimension, i.e. on brand activity and brand efficiency. The brand name containing front vowel was rated better when subjects evaluated the product in generally. Last, but not least, when it comes to convey meanings, the sound of back vowels [a] could be used more when marketers promote products that communicate its characteristics such as efficiency, velocity and health. The back vowel could be also assessed to products with larger packing or special sailing such as extra quantity. Meanwhile, the brand names with front vowels [ie] could be created for more expensive products with good quality, mainly addressed to men.
\end{abstract}

\section{Keywords}

brand name; sound symbolism; advertising; social psychology; semantic differential

\section{JEL Classification}

M31

\section{Introduction}

The term "sound symbolism" has been recently employed by scholars from different areas of study (Marketing, Advertising, Social Psychology and Communication Studies) in order to acknowledge the importance of phonemes - either vowels or consonants - in the process of advertising different goods and services. It is commonly accepted that any spoken language has its own rules of combining sounds so as to turn them into words. Furthermore, the physiologic condition of streaming the sounds (encode) - either with or without stressing - elicits different decoding processes of the receptors.

Based on these assumptions derived mainly form linguistics, scholars have already began to test the effectiveness of sounds (i.e. vocals or consonants - phonemes) on consumer's preferences and purchasing decisions. For example, Yorkston and Menon (2004) created two fictitious brand names for ice cream, Frish and Frosh, by manipulating only the vowel sound, such as: the [i] sound in Frish is more of a front 
vowel sound than the [a"] sound in Frosh. The participants tended to associate the [a"] with attributes such as bigger, heavier, duller and slower as compared to sound [i]. Consequently, the Frosh brand was perceived as smoother, richer, and creamier than the Frish brand name and it was preferred among the potential consumers (Yorkston and Menon, 2004).

Brand specialists and scholars voiced concern over the effect of brand names on consumer perception, for instance the Ford Edsel has been attributed to a poor brand name (Klink, 2001); Mazda (Chile division) rename its Laputa minivan because "puta" means "prostitute" in Spanish; Clairol introduced the Mist Stick curling iron in Germany without observing that "mist" is slang for "manure" (Fetscherin, Alon, Littrell \& Chan, 2012). All these examples refer to the automatic inference that consumers could make as a result of pairing the phonemes (i.e., how words sound) with cultural aspects of a semantic unit (i.e. how sounds/words connote meaning).

\section{Sound symbolism and perceived characteristics of brands}

There is little doubt that branding represents a crucial stage in positioning the products and services (Keller, 2003; Lindsdrom, 2005) as studies related to this topic have been flourished worldwide. Nevertheless, it was only recently that the marketers have paid attention to the research regarding sound symbolism. Fifty years ago, the restrained interest on the effects of sounds symbolism on marketing could be counted on poor disseminations of research outside the academic laboratory as well as on the limited connection between marketing and linguistics. In a pioneering study (Sapir, 1929) conducted mostly on cross-cultural samples, Sapir (1929) asked Englishspeaking subjects to associate two apparently meaningless words, mil and mal, with a small and a large table. A large percentage of English speaking subjects - that is $80 \%$ of them - assessed mal to a large table and mil to a small one. Following Sapir, other scholars asserted that certain sounds do have effects in real language. For instance, Jespersen (1922) emphasized that back vowels such as the [u] sound in dull or ugh are often found in English words expressing disgust or dislike (e.g., blunder, bung, bungle, clumsy, muck), and words beginning with sl also tend to have a negative connotation (slouch, slut, slime, sloven). Words beginning with $f l$ often express movement (flutter, flap, flicker) (apud Lowrey and Shrum, 2007). Similarly, Smith (1998) proved that brand names or people's names that contain either back vowel sounds or begin with sl are perceived as less positive than others names. On this purpose, he analyzed U.S. presidential election outcomes, from 1824 to 1992, and found out that the more a family name of the candidates was related to a negative sound (such as $s l, f l$ or $u$ ), the fewer his chances to win the election were.

Research regarding sound symbolism have been conducted on languages around the world, highlighting similarities and contrasts in conveying word meaning. Brown (1958) suggested that words connoting "little" in non-English languages - such as kleine (German), petite (French), piccola (Italian), and mikros (Greek) - have front vowel sounds as the initial syllable. The same is true for suffixes: Diminutives in English are made by adding ie, in Spanish ico and ito, and in Italian ino (apud Lowrey and Shrum, 2007).

Since the beginning of the 2000s, Richard Klink's (2000, 2001, 2003, 2009) influential works had been successfully applied the principles of phonology into the marking research. After a systematic review of sound symbolism studies, Klink (2000) empirically reviled that products with brand names containing front vowels, as opposed to back vowels, are perceived as smaller, lighter (relative to darker), milder, thinner, softer, faster, colder, more bitter, more feminine, friendlier, weaker, lighter (relative to heavier), and prettier. In his experiment, subjects perceived the brand names containing fricatives, as opposed to stops, as smaller, faster, lighter (as 
opposed to heavier), and more feminine. With respect to conveying sharpness or softness, he did not obtained significant outcomes either the names containing stops or fricatives. Furthermore, products with brand names containing voiceless stops, as opposed to voiced stops, were perceived as smaller, faster, lighter (relative to heavier) sharper, and more feminine. Similarly, brands containing voiceless fricatives, as opposed to voiced fricatives, were perceived as faster, softer, and more feminine.

The outcomes of Klink's studies were further replicated. In this respect, Yorkston and Menon (2004) stated that the processing of brand names and their sound symbolism effects imply automatic cognition processes such as the effortless strategy of the mind. Based on above mentioned research (i.e. Yorkson \& Menon, 2004), Lowrey and Shrum (2007) were interested to observe how much an individual links a vowel or consonant sounds with a certain characteristics of a product. Specifically, they juxtaposed two-seater convertible (smaller, faster, lighter) with sport utility vehicle (SUV; larger, slower, heavier), and knife (sharper) with hammer (duller). They assumed that subjects "would prefer words with front vowel sounds as brand names over words with back vowel sounds when the product categories were two-seater convertible and knife, but would prefer those very same back vowel sound words as brand names over the same front vowel sound words when the product categories were SUV and hammer" (Lowery \& Shrum, 2007, 409). The results showed that: "Sounds of words appear to convey meaning apart from the denotative meaning of the words, and people spontaneously apply these meanings when fitting brand names with products. When the sounds of the words are associated with certain attributes (small, sharp), the words are preferred as brand names for products in which those attributes are favorable (convertible, knife). Conversely, when the sounds of the words are associated with an opposite meaning (large, dull), they are preferred for product categories for which those attributes are considered appropriate (SUV, hammer)" (Lowery \& Shrum, 2007, 411)

Klink (2009) argued that certain sounds of the brand names can better target the products on the market, meaning that front vowels were received more favorably by females as compere with brand-back vowels which are better evaluated by males, particularly in product categories where masculinity-femininity is a more salient product attribute (e.g., deodorants vs. paper clips).

Recently, Wu, Klink and Guo (2013) tested the relation between the meaning of a sound and brand personalities (masculine either feminine) in three artificial brand name pairs such as following: Mig/Mog for spring water, Riv/Rov for deodorant, Frish/Frosh for vitamin C, and Zid/Zod for body wash. Half of the participants (the "gender targeting group," $\mathrm{N}=48$ ) were informed that "the brand is specially design for women/men" (i.e., spring water and deodorant for women; vitamin C and body wash for men), while the other half did not receive this information (the "non-gender targeting group," 49 respondents). The "non-gender targeting group" represented the control group. The results of the experiment support the effect of phonetic symbolism on consumers' perception of gender brand personality. Specifically, back vowel sounds were associated with the masculine personalities (adventurous, aggressive, brave, daring, dominant, and sturdy), whereas front vowel sounds were related to the feminine brand personalities (expressing tender feelings, fragile, graceful, sensitive, sweet, and tender). Moreover, when respondents were instructed that a brand is designed for a particular gender, they demonstrated differential preferences according to the two vowel types, namely, brand names with front (back) vowels were chosen for brands targeting women (men). When no gender related instructions were provided, the respondents indicated little to no preferences for brand names with front or back vowels. 


\section{Methodology}

As previous research showed, the phonetic structure of brand name communicates its characteristics, i.e. it drives consumers to assess certain features and performance of the product. I assumed that when consumers encounter an unknown brand name, they automatically infer characteristics from the meaning conveyed by the sounds (e.g. phonemes). Therefore, I supposed that a brand name for a shampoo (artificially created on experimental purpose) containing back vowels (Gameli) is evaluated better by consumers when they compare it to another brand name with front vowels (Giameli).

\section{Hypothesis}

Based on the previous research, I framed and tested the following four hypotheses:

Hypothesis 1. The subjects will probably evaluate the proprieties of a brand name containing back vowel (i.e. Gameli) better than a brand name containing front vowel (i.e. Giameli).

Hypothesis 2. The subjects will probably evaluate the performance of a brand name containing back vowel (i.e. Gameli) better than a brand name containing front vowel (i.e. Giameli).

Hypothesis 3. The subjects will probably evaluate a brand name containing back vowel (i.e. Gameli) as more efficient (i.e. in this case, the efficiency in hair-loss treatment shampoo) than a brand name containing front vowel (i.e. Giameli).

Hypothesis 4. The subjects will probably perceive the name with back vowels (Gameli) as more feminine than a brand with front vowel (i.e. Giameli).

\section{Procedure, sample and developing of questionnaire}

Fifty $(\mathrm{N}=50)$ students enrolled in a Social Psychology Master level course participated in a study for an extra credits in December 2014. Participants were aged between $23(\mathrm{~N}=36)$ and $24(\mathrm{~N}=14)$. As regarding to gender, thirty of them were female $(\mathrm{F}=30)$, and the rest of them male $(\mathrm{M}=20)$. They had to fill in a questionnaire regarding the evaluation of two fictitious brand names for a shampoo that prevent hair-loss (Gameli/Gimeli). The brand names have been created according to the Romanian principles of phonology (Slama-Cazacu, 1999; Avram, 1961). Consequently, I manipulated only two phonemes: front vowel (Giameli) and back vowel (Gameli). I asked subjects to choose from a bipolar list of attributes certain characteristics that could be assessed for the two shampoo brand names (Giameli/Gameli). For measuring the perceived characteristics of a brand as well as for its evaluation and performance, I used the semantic differential rating scale (Osgood, 1964) with 9-bipolar adjectives such as: good quality-bad quality; expensive-cheap; healthy-unhealthy; slow-fast; weak-strong; inefficient-efficient; feminine-masculine; insufficient-abundant; large-scale-small-scale. The subjects were asked to choose where his/her position lies on a scale (with 8 points) between two bipolar adjectives. Then the responds were grouped according to three factors (EPA evaluation, power and activity): brand evaluation (good quality-bad quality; expensive-cheap; insufficient-abundant), brand activity (inefficient- efficient; slowfast; healthy-unhealthy) and power/brand efficiency (weak-strong; large-scale-smallscale; masculine-feminine). The date was computed using SPSS version 20.

Secondly, the questionnaire also assessed the preferences of the respondents concerning Romanian letters and its orthography, the frequency of using hair loss shampoo and socio-demographics (gender, age, income, education, residence). 


\section{Results}

Perceived attributes of the brands. As we can see from the Table 1, the brand name containing front vowel (Giameli) was perceived as more positive than the brand with back vowel (Gameli) on all nine attributes. On average, Giameli is evaluated by subjects as better $(M=4,43)$, cheaper $(M=4,71)$, healthier $(M=4,74)$, faster $(M=4,46)$, stronger $(M=4,68)$ and more efficient $(M=4,86)$ than Gameli. The brand with front vowels (Giameli) it was also assessed as being masculine $(M=4,44)$ and small scale dimension $(\mathrm{M}=4,64)$ compared with Gameli which was perceived as feminine $(\mathrm{M}=3,27)$ and large-scale dimension $(\mathrm{M}=4,55)$.

Table 1. Attributes assigned to each brad on average

\begin{tabular}{|l|c|c|l|}
\hline & GAMELI & GIAMELI & \\
\hline Bad Quality & 3,51 & 4,43 & Good Quality \\
\hline Expensive & 3,57 & 4,71 & Cheap \\
\hline Unhealthy & 3,89 & 4,76 & Healthy \\
\hline Slow & 3,47 & 4,46 & Fast \\
\hline Weak & 3,91 & 4,68 & Strong \\
\hline Inefficient & 4,00 & 4,86 & Efficient \\
\hline Feminine & 3,27 & 4,44 & Masculine \\
\hline Insufficient & 4,00 & 4,34 & Abundant \\
\hline Large scale & 4,55 & 4,64 & Small scale \\
\hline
\end{tabular}

The profile of the brands. As a result of using a semantic differential scale when measured the perceived of characteristics of the two brand (Giameli and Gameli) I illustrate (Figure 1) the profile of the two studied brands. The Figure no. 1 highlights the differences between the two brands in terms of attributes, i.e. how much a brand is closer or farther from a positive pole than the other.

\begin{tabular}{|c|c|c|c|c|c|c|c|c|}
\hline & 1 & 2 & 3 & 4 & 5 & 6 & 7 & \\
\hline Bad Quality & & & & $\bullet$ & & & & Good Quality \\
\hline Expensive & & & & $!$ & & & & Cheap \\
\hline Unhealthy & & & & ! & & & & Healthy \\
\hline Slow & & & & d & & & & Fast \\
\hline Weak & & & & i & & & & Strong \\
\hline Inefficient & & & & $\bullet$ & & & & Efficient \\
\hline Feminine & & & & $\bullet$ & & & & Masculine \\
\hline Insufficient & & & & & & & & Abundant \\
\hline Large scale & & & & $b$ & & & & Small scale \\
\hline
\end{tabular}

Figure 1. The bipolar profiles of the brand names 
Brand evaluation, activity and power. The outcomes of ranking products according to their characteristics, namely how much the subjects believed that the two brands (Giameli and Gameli) are better in terms of their activity, efficiency and cognitive evaluation are presented in the Table no.2. As we can observe, the brand name with back vowel (Gameli) outnumbers Giameli (brand with back vowel) on two factors related to brand activity (inefficient- efficient; slow-fast; healthy-unhealthy) and brand efficiency (weak-strong; large-scale-small-scale; masculine-feminine). The brand name containing front vowel (Giameli) scores better $(M=16,67)$ only when it comes with cognitive evaluation of a product (good quality-bad quality; expensivecheap; insufficient-abundant) as compared with Gameli $(\mathrm{M}=16,62)$, but the differences between them (on average) are not statistical significant.

Table 2. EPA scores for each brad, on average

\begin{tabular}{|c|c|c|c|c|c|c|c|}
\hline \multicolumn{2}{|c|}{ BRAND NAME } & $\begin{array}{c}\text { Evaluation } \\
\text { Positive }\end{array}$ & $\begin{array}{c}\text { Power } \\
\text { Positive }\end{array}$ & $\begin{array}{l}\text { Activity } \\
\text { Positive }\end{array}$ & $\begin{array}{c}\text { Evaluation } \\
\text { negative } \\
\text { GIAMEL }\end{array}$ & $\begin{array}{c}\text { Power } \\
\text { negative }\end{array}$ & $\begin{array}{c}\text { Activity } \\
\text { negative }\end{array}$ \\
\hline \multirow{3}{*}{$\sum_{0}^{|c|}$} & Mean & 16,67 & 15,50 & 15,60 & 8,60 & 8,56 & 7,50 \\
\hline & $\mathbf{N}$ & 9 & 6 & 10 & 5 & 9 & 8 \\
\hline & $\begin{array}{l}\text { Std. } \\
\text { Deviation }\end{array}$ & 1,732 & 837 & 3,062 & 3,362 & 3,046 & 2,976 \\
\hline \multirow{3}{*}{ 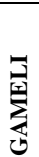 } & Mean & 16,62 & 18,00 & 18,30 & 5,57 & 4,50 & 5,57 \\
\hline & $\mathbf{N}$ & 13 & 7 & 10 & 4 & 4 & 7 \\
\hline & $\begin{array}{l}\text { Std. } \\
\text { Deviation }\end{array}$ & 2,959 & 1,528 & 27,510 & 1,258 & 2,380 & 2,878 \\
\hline
\end{tabular}

\section{Conclusion}

In this article, I provided empirical support for three of the four assumptions. Generally, subjects evaluate better the brands containing front vowels [ie] than back vowels [a], in this case the brand Giameli as better $(M=4,43)$, cheaper, healthier, faster, stronger and more efficient than Gameli. Although, when measuring the brand rating according with three factors such as brand performance, brand efficiency and brand evaluation (cognitive) using the semantic differential scale, the results are more specific. As the outcomes of the research showed, the brand name with back vowel (Gameli) outnumbers Giameli (brand with back vowel) on two factors relating to brand activity (inefficient- efficient; slow-fast; healthy-unhealthy) and brand efficiency (weak-strong; large-scale-small-scale; masculine-feminine). The brand name containing front vowel (Giameli) was rated better $(M=16,67)$ only when it comes with cognitive evaluation of a product (good quality-bad quality; expensivecheap; insufficient-abundant) as compared with Gameli, but the differences on averages are not statistical significant. As a result of questioning the influence of front and back vowels within the brand name, I can say that a product containing back vowels [a] could be created when advertisers want to promote a brand that could be automatic assessed to characteristics such as efficient, faster, healthier, stronger, with larger packing. Meanwhile, the brand names with front vowels [ie] could be linked to more expensive products with good quality, mainly addressed to men targets.

When it comes to convey meanings and communicating characteristics, as the results of the present research revealed, Romanian back vowels [a] possess an inherent meaning of womanliness while front vowels [ie], in this case the [ie] from Giameli, are perceived as more masculine than word with [a], Gameli. In this respect, our 
research is similar with previous ones (Klink, 2000; Yorkston \& Menon, 2004; Lowrey \& Shrum, 2007; Klink, 2009) regarding the effect of back vowels on brand characteristics. In Romanian language, girls' first names and feminine nouns often end in $a$. Consequently, most subjects from our research assigned feminine characteristics to a brand name that contains an emphasis on the vowel [a]. On the other hand, we can explain these results taking into account that in the current sample females outnumber males. The larger presence of women $(\mathrm{F}=30)$ as compared to men $(\mathrm{M}=20)$ could led to the preference for more feminine words (in this case, Gameli) and, consequently, to their meaning of womanliness.

Following the outcomes of present research, I obtained an effect of front and back vowels when the subjects assess the performance of shampoo that prevent hair loss. As I mentioned above, when it comes to convey meanings, the sound of back vowels [a] could be used more when marketers promote products that communicate characteristics such as efficiency, velocity, health. The back vowel could be also assessed with products with larger packing or special sailing such as extra quantity. Meanwhile, the brand names with front vowels [ie] could be created for more expensive products with good quality, mainly addressed to men.

To conclude, several limits must be taken into account, such as the short number of participants in the study and their similarities in terms of socio-demographics characteristics. Further research on phonetic symbolism could investigate how other variables, for instance the type of product (food, electronics, automobiles, body care products) and the other socio-demographics (income, education) fit with the sounds as well as with the concept of the brand. Nevertheless, the current study could be considered the second stage in researching the brand names effects on young consumers (Duduciuc \& Ivan, 2014) and could be link to the similar attempts (Chelcea, 2012) to develop the applied advertising research in Romania.

\section{Acknowledgements}

This paper was possible with the financial support of the Sectorial Operational Programme for Human Resources Development 2007-2013, co-financed by the European Social Fund, under the project number POSDRU/159/1.5/S/134650 with the title "Doctoral and Postdoctoral Fellowships for young researchers in the fields of Political, Administrative and Communication Sciences and Sociology".

\section{References}

Avram, A. (1961), Cercetări asupra sonorității în limba română, București: Editura Academică.

Chelcea, S. (2012), Psihosociologia publicității: despre reclame vizuale, Iași, Editura Polirom.

Duduciuc, A., Ivan, L., (2014). Brand naming: sound symbolism, brand preference and brand performance, Studies and Scientific Research. Economics Edition, 20, 79-85.

Fetscherin, M., Alon, I., Littrell, R., Chan, A. (2012), In China? Pick Your Brand Name Carefully, Harvard Business Review, Available at https://hbr.org/2012/09/in-china-pick-your-brand-name-carefully

Klink, R.R. (2000), Creating Brand Names with Meaning: The Use of Sound Symbolism, Marketing Letters, 11 (1), 5-20.

Klink, R.R. (2001), Creating meaningful new brand names: a study of semantics and sound symbolism, Journal of Marketing Theory and Practice, 9 (2), 27-34. 
Klink, R.R. (2003), Creating meaningful brands: the relationship between brand name and brand mark, Marketing Letters, 14 (3), 143-157.

Klink, Richard R. (2009), Gender Differences in New Brand Name Response, Marketing Letters, 20 (3), 313-326.

Lindsdrom, M. (2005), Build Powerful Brands through Touch, Taste, Smell, Sight, and Sound, New York, Free Press.

Lowrey, T.M., Shrum, L.J. (2007), Phonetic Symbolism and Brand Name Preference, Journal of Consumer Research, 34 (3), 406-414.

Osgood, C.E. (1964), Semantic differential technique in the comparative study of cultures. American Anthropologist, 66(3), 171-200.

Sapir, Edward (1929), A Study in Phonetic Symbolism, Journal of Experimental Psychology, 12 (3), 225-239.

Slama-Cazacu, T. ( 1999), Psiholingvistica - o știință a comunicării, București:

Editura All.

Smith, Grant W. (1998), The Political Impact of Name Sounds, Communication Monographs, 65 (June), 154-72.

Wu, L., Klink, R. R., Guo, J. (2013). Creating Gender Brand Personality with Brand Names: The Effects of Phonetic Symbolism, Journal of Marketing Theory and Practice, 21, (3), 319-329.

Yorkston, E., Menon, G. (2004). A Sound Idea: Phonetic Effects of Brand Names on Consumer Judgments, Journal of Consumer Research, 31 (1), 43-51. 